ISBN 978-81-933894-1-6

International Conference on Studies in Disaster Management, Civil and Architectural Engineering

(SDMCAE-17)

Kyoto (Japan) April 18-19, 2017

\title{
Development of Indicators For Formulation of Disaster Preparedness Indices in the Indian Context
}

\author{
Shine George ${ }^{1}$, Anilkumar P P ${ }^{2}$ \\ ${ }^{1}$ Research Scholar, Department of Architecture and Planning, National Institute of Technology, NIT Campus \\ P.O., Calicut, 673 601, India \\ ${ }^{2}$ Associate Professor, Department of Architecture and Planning, National Institute of Technology, NIT Campus \\ P.O., Calicut, 673 601, India
}

\begin{abstract}
The increasing risk of natural disasters poses a major challenge to sustainable development; as disasters often undermine progress in unpredictable ways, shattering developmental efforts. Recent initiatives are targeted towards spreading the culture of disaster risk reduction so as to check eroding developmental gains caused by the occurrence and recurrence of disasters. Relief-centric approach has been relegated to the background; according more importance to a more pro- active preparedness-driven approach. India, the second-most populous country, is vulnerable in varying degrees to a wide range of natural disasters owing to its unique, diverse geo-climatic conditions. Given this, the need for disaster preparedness measures as well as effective means to assess them is accentuated. Despite the launching of several successful projects and programmes on disaster mitigation and management in India, a streamlined system of data collection for emergency response and a well-articulated metric to gauge disaster preparedness still remains a significant challenge. There are not many reliable and perceptible methods to measure the country's capacity to respond to disasters, gauging all aspects of disaster preparedness and coping capacities by employing low-end and affordable technology. The domain of disaster preparedness being very complex; construction of easilycomprehensible assessment frameworks with well-defined indicators is the need of the hour, though complicated to conceive. This paper proposes a set of indicators which could be used to construct comprehensive disaster preparedness indices. Such indices enable key stake-holders to assess strengths and weaknesses of their systems and serve as a vital tool to improve preparedness efforts. It may help sensitize political and administrative decision makers on the capacity of emergency management systems to handle a disaster and thereby lead to a more efficient allocation of scarce resources. Further, the critical variables pertinent to disaster preparedness and emergency management are identified and validated by conducting an expert questionnaire survey. A set of sector-wise core indicators and their influencing attributes; which collectively capture disaster preparedness aspects in the Indian perspective are developed. These may contextually be applicable to other developing countries as well. A concise account of the variables with key information about their content, data requirements and proposed data sources are also identified. This would help organize information for easy reference, candid response in case of disasters and also to monitor disaster preparedness on a continuous basis for improved resilience.
\end{abstract}

Keywords: Disaster Preparedness Indices, Indicators, Natural Disasters, Indian context

\section{Introduction}

The approach towards disaster management in India over the past decade has undergone a major paradigm shift. Relief- centric approach has been relegated to the background; according more importance to a more proactive preparedness-driven approach [1]. This approach proceeds from the conviction that development cannot be sustainable unless disaster mitigation is built into the development process; as disasters often undermine progress in unpredictable ways, shattering developmental efforts. Recent initiatives are targeted towards 
spreading the culture of disaster risk reduction so as to check eroding developmental gains caused by the occurrence and recurrence of disasters. India, the second-most populous country, is vulnerable in varying degrees to a wide range of natural disasters owing to its unique, diverse geo-climatic conditions. Given this, the need for disaster preparedness measures as well as effective means to assess them is accentuated. There are not many reliable and perceptible methods to measure the country's capacity to respond to disasters, gauging all aspects of disaster preparedness and coping capacities by employing low- end and affordable technology. Despite the launching of several successful programmes on disaster mitigation and management, a streamlined system of data collection for emergency response and a well- articulated metric to gauge disaster preparedness still remains a significant challenge. The domain of disaster preparedness being very complex; construction of easily-comprehensible assessment frameworks with well-defined indicators is the need of the hour, though complicated to conceive.

\section{Disaster Preparedness Indices (DPI)}

The Sendai Framework for Disaster Risk Reduction 2015-2030 which was adopted at the Third UN World Conference in Sendai, Japan, identified the enhancement of disaster preparedness for effective response and to "Build Back Better" in recovery, rehabilitation and reconstruction as a major priority [2]. Preparedness relates to activities and measures taken in advance to ensure effective response to the impact of hazards. The identification of coping capacities and indicators designed and developed to quantify them would yield a measure of disaster preparedness. Preparedness indices are formulated by way of these indicators to measure how effectively the government, the civil society and the bodies responsible for prevention and management of disasters anticipates and prepares for; manages and responds to the impact of natural disasters [3]. The creation and use of an "index" has been a popular methodology for evaluating relative levels of some state of being, whether economic health, quality of life, or vulnerability to natural hazards [4]. An overview of literature reveals that efforts have been undertaken by various organizations across the globe to design indicators and indices which would reflect their innate and developed capacities in specific aspects of management and mitigation of disasters. Such an index enables the key stake- holders to assess and compare in great depth the strengths and weaknesses of their systems and serves as a vital tool to further improve their preparedness efforts. This paper attempts to identify indicators which may be used for constructing disaster preparedness indices which would remain sensitive to the Indian context.

\section{Methodology}

It was imperative to understand the measures adopted by other countries in the realm of disaster preparedness and its assessment so as to comprehend its scope and extent of applicability in the Indian context. A detailed review of literature was performed on case studies, various UN reports, journals and articles in the domain of disaster preparedness and risk reduction; and on manuals and guidelines pertaining to construction of measurement indices and indicators. Studies on Disaster Preparedness practices and initiatives led by various agencies were referred to; specifically in South Asian, African and Caribbean countries, which devised measurement systems to assess the same. Further, a questionnaire was formulated and administered among stake- holders and experts from varied realms of disaster management; and their responses were analyzed to capture the elements of disaster preparedness and to identify the key indicators to measure the same in the Indian context. Taking into account the nature of indicators which may not always be directly quantifiable, expert judgment was elicited not only for the selection of core indicators and the corresponding influencing attributes but also for assigning their relative weightings. Many researchers have long supposed that expert opinion method for assessment of disaster risk/ preparedness indicators on an ordinal scale by stakeholders with a high degree of knowledge on the system at stake would yield excellent results [5], [6], [7]. Accordingly, the questionnaire was administered among 7 identified categories of experts. They were drawn from Academic and Research Institutions of repute in India, NGOs, Development Authorities, Consultant organizations, general 
public, affected stake-holders and related Government establishments across the states of Kerala, Karnataka, Tamilnadu and Gujarat.

\section{Desirable Qualities of Indicators for Disaster Preparedness}

For a variable to be a good indicator of what it purports to represent, the statistical production processes used to develop it needs to be methodologically sound, follow appropriate procedures, be consistent and complementary, limited in numbers and relevant to its users [8]. Indicators also need to be practical and costeffective in terms of measurability, without imposing an excessive burden on respondents. Based on the criteria applied for selection of indicators used in the construction of Earthquake Disaster Risk Indices (EDRI) by Davidson and Shah [5], Simpson [4] and Sendai Framework [2], the following criteria should guide the indicator selection process for DPI [9]:

- Validity: The indicators should be analytically sound. The type, depth, scope, and appropriateness of the indicator should carefully be probed upon.

- Data availability and quality: The indicators should be measurable through reliable data, available consistently. In the Indian context, the availability, credibility and quality of data are criteria which may not be easy to comply.

- Tangibility and objectivity: The indicators should be quantifiable and of an objective nature so that DPI may be more easily evaluated than with data which requires subjective assessment.

- Clarity: Indicators should correspond to data sets with familiar concepts and quantities whenever possible. It should have a precise meaning.

- Directness: An indirect indicator being not as valid and accurate as a direct one, direct indicators are always preferable if they are available.

In addition to these, UNDP, 2014, proposes the following desirable qualities of indicators- accuracy, appropriate spatial and temporal resolution, coherence, comparability, interpretability, timeliness, focus on outcomes, possibility to get disaggregated data and a responsible agency for producing data [10].

\section{Development of Indicators in the Indian Context}

To quantify disaster preparedness both inductive and deductive approaches have to be employed. In the inductive approach it is necessary to 'induct' or develop a set of indicators and formulate methods to measure them. In the deductive approach independent measurements which directly capture preparedness aspects may be made use of. Circular logic, being an inherent fallacy associated with inductive approach was taken care of by adopting subjective surveying undertaken by administering a questionnaire among different stake-holders concerning their perceptions on disaster preparedness. The indicators and sub- indicators were liberally and deliberately sourced from the directives discussed in Sendai Framework 2015-2030 and the succeeding technical deliberations undertaken by UNDP during the past year, they being conceded as the most relevant and recent developments in the field of disaster risk reduction and management. The seven factors of disaster preparedness identified as core indicators are listed below:

\subsection{Contingency Planning}

Contingency planning relates to those aspects of planning where-in response objectives and strategies are clearly defined; as indigenous coping mechanisms and measures to strengthen resilience are indicative of the efficacy of a preparedness initiative.

\subsection{Capacity Analysis and Capacity Building}

Capacity analysis is expected to measure available resources and operational facilities and attributes pertinent to involvement of technical agencies and academia in capacity building initiatives.

\subsection{Hazard Monitoring, Forecasting and Early Warning Systems}


This core indicator captures the aspects of reach, reliability, quality and legislation pertaining to generation and dissemination of hazard warnings.

\subsection{Information Management and Communication Systems}

This indicator gauges the modes and resources for handling media relations; creation, maintenance and updating of a database/ case registry to store hazard risk information and disaster statistics.

\subsection{Emergency Services}

The attributes of this core indicator are provisions for a well-equipped Emergency Operations Centre for multi-agency coordination, decision-making and management of information.

\subsection{Resource Allocation}

This core indicator takes care of budgetary allocations as a whole and legislation pertinent to it.

\subsection{Incorporation of Early Recovery into Preparedness Planning}

This indicator relates to transitional interventions vide provision of basic services and shelter; measures to sustain livelihood; and measures for implementing early recovery after a disaster.

To depict the relative importance of each contributing indicator to the index measurement, weightings were assigned to each indicator. The core indicators identified through AHP (Analytical Hierarchy Process) questionnaire and the respective weightings to be assigned to them are tabulated as follows:

TABLE I: WEIGHTINGS FOR CORE INDICATORS BASED ON AHP

\begin{tabular}{lccccccc}
\hline \hline Indicator & $\begin{array}{c}\text { Contingency } \\
\text { Planning }\end{array}$ & $\begin{array}{c}\text { Capacity } \\
\text { analysis and } \\
\text { capacity } \\
\text { building }\end{array}$ & $\begin{array}{c}\text { Hazard } \\
\text { monitoring } \\
\text { forecasting } \\
\text { and early } \\
\text { warning }\end{array}$ & $\begin{array}{c}\text { Information } \\
\text { management } \\
\text { and } \\
\text { communication } \\
\text { systems }\end{array}$ & $\begin{array}{c}\text { Emergency } \\
\text { services }\end{array}$ & $\begin{array}{c}\text { Resource } \\
\text { allocation }\end{array}$ & $\begin{array}{c}\text { Incorporation } \\
\text { of early } \\
\text { recovery into } \\
\text { preparedness } \\
\text { planning }\end{array}$ \\
\hline Weighting & 0.08 & 0.11 & 0.19 & 0.07 & 0.36 & 0.06 & 0.13 \\
\hline \hline
\end{tabular}

\section{Identification of Sub-Indicators and their Relative Weightings}

The attributes pertinent to each core indicator were termed as sub-indicators. Once the core indicators were identified, the next step was to identify sub- indicators for each of them. The weightings to be assigned to the sets of sub- indicators were drawn through expert judgment assimilated by means of a standardized questionnaire. A concise account of the indicators with key information about content, data requirements and proposed data sources are as tabulated below.

Since indicators were chosen through subjective assessments by way of questionnaire surveys, problems arising out of different perspectives may be anticipated. Proper statistical, numeric techniques may be adopted for verification of their sensitivity and uncertainty and for aggregation of these indicators into a comprehensive DPI. Further, Disaster Preparedness Indices are intended to capture the diverse and varied geo-climatic conditions prevalent in India. To address and even these out, the group of seven core indicators identified here could further be corroborated with another set of secondary data which reflect those dimensions of contextual differences. The identification of secondary datasets was beyond the scope of this paper. 
TABLE II: WEIGHTINGS, DATA SOURCES FOR SUB INDICATORS BASED ON EXPERT JUDGMENT

\begin{tabular}{|c|c|c|c|}
\hline Core Indicator & Sub-Indicators & Weighting & Data Sources \\
\hline $\begin{array}{l}\text { Contingency } \\
\text { Planning }\end{array}$ & $\begin{array}{l}\text {-Integration of multi-hazard assessment and vulnerability/ risk analysis into } \\
\text { plans } \\
\text {-Simulation and response exercises conducted } \\
\text {-Periodic revision with consultative dialogues with stakeholders } \\
\text {-Inclusion of indigenous coping mechanisms, measures to strengthen } \\
\text { resilience } \\
\text {-Clarity in defining response objectives and strategies }\end{array}$ & $\begin{array}{l}0.14 \\
0.23 \\
0.19\end{array}$ & $\begin{array}{l}\text { Primary and secondary } \\
\text { datasets } \\
\text { Local administration } \\
\text { District, State, National } \\
\text { Disaster Management } \\
\text { Authority }\end{array}$ \\
\hline $\begin{array}{l}\text { Capacity } \\
\text { analysis and } \\
\text { capacity } \\
\text { building }\end{array}$ & $\begin{array}{l}\text {-Available resources, operational facilities at every level } \\
\text {-Operational plans, standards, protocols and procedures } \\
\text {-Communications and coordination systems } \\
\text {-Development, implementation of appropriate training programmes, } \\
\text { simulation exercises } \\
\text {-Consistent, timely budgetary allocations for institutional capacity building, } \\
\text { technical training } \\
\text {-Involvement of specialised technical agencies and academia in capacity } \\
\text { building initiatives }\end{array}$ & $\begin{array}{l}0.17 \\
0.22 \\
0.15 \\
0.16\end{array}$ & $\begin{array}{l}\text { National Database for } \\
\text { Emergency Management } \\
\text { (NDEM) } \\
\text { National Spatial Data } \\
\text { Infrastructure } \\
\text { (NSDI) } \\
\text { District, State and National } \\
\text { Disaster Management } \\
\quad \text { Authority }\end{array}$ \\
\hline $\begin{array}{l}\text { Hazard } \\
\text { monitoring } \\
\text { forecasting and } \\
\text { early warning }\end{array}$ & $\begin{array}{l}\text {-Legislation pertaining to generation and dissemination of hazard warning } \\
\text {-Development of local, national and regional risk and multi-hazard maps } \\
\text {-Provisions for periodic testing and modification as per standards and guides } \\
\text {-Reach, reliability and quality of warning systems } \\
\text {-Public awareness strategies and programmes } \\
\text {-Involvement of specialised technical agencies and academia }\end{array}$ & $\begin{array}{l}0.23 \\
0.14 \\
0.12\end{array}$ & $\begin{array}{l}\text { India Disaster Resources } \\
\text { Network } \\
\text { (IDRN) } \\
\text { Portal } \\
\text { DESINVENTAR } \\
\text { District, State and National } \\
\text { Disaster Management } \\
\text { Authority }\end{array}$ \\
\hline $\begin{array}{l}\text { Information } \\
\text { management and } \\
\text { communication } \\
\text { systems }\end{array}$ & $\begin{array}{l}\text {-Modes and resources for handling media relations } \\
\text {-Modes for collection, compilation, dissemination of temporal information on } \\
\text { hazards, vulnerabilities, and capacities } \\
\text {-Creation, maintenance and updating of a GIS database/ case registry to store } \\
\text { hazard risk information and disaster statistics } \\
\text {-Accessibility of data } \\
\text {-Mass media campaigns to increase public awareness }\end{array}$ & 0.20 & $\begin{array}{c}\text { National Database for } \\
\text { Emergency Management } \\
\text { (NDEM) } \\
\text { National Spatial Data } \\
\text { Infrastructure } \\
\text { (NSDI) } \\
\text { District, State,National } \\
\text { Disaster Management } \\
\text { Authority } \\
\end{array}$ \\
\hline $\begin{array}{l}\text { Emergency } \\
\text { services }\end{array}$ & $\begin{array}{l}\text {-Adherence to SPHERE standards [11] } \\
\text {-Availability of human, physical and logistics resources } \\
\text {-Provisions for hazard damage assessment and documentation } \\
\text { Provisions for a well-equipped Emergency Operations Centre for multi- } \\
\text { agency coordination; decision-making, information management } \\
\text {-Provisions to document experiences during hazard events and disasters to } \\
\text { assist post-disaster reviews }\end{array}$ & $\begin{array}{l}0.12 \\
0.26 \\
0.19 \\
0.28\end{array}$ & $\begin{array}{c}\text { National Database for } \\
\text { Emergency Management } \\
\text { (NDEM) } \\
\text { National Spatial Data } \\
\text { Infrastructure } \\
\text { (NSDI) District, State and } \\
\text { National Disaster Management } \\
\text { Authority }\end{array}$ \\
\hline $\begin{array}{l}\text { Resource } \\
\text { allocation }\end{array}$ & $\begin{array}{l}\text {-Budgetary allocations } \\
\text {-Legislation for relief funds and replenishment of the same } \\
\text {-Policies, protocols, procedures for other funding mechanisms } \\
\text {-Procurement procedures for external resources (in-kind donations, incoming } \\
\text { relief items) } \\
\text {-Government social protection programmes partnered with private sector } \\
\text { service providers }\end{array}$ & $\begin{array}{l}0.30 \\
0.25 \\
0.19 \\
0.12\end{array}$ & $\begin{array}{c}\text { Local administration } \\
\text { District, State and National } \\
\text { Disaster Management } \\
\text { Authority }\end{array}$ \\
\hline $\begin{array}{l}\text { Incorporation of } \\
\text { early recovery } \\
\text { into } \\
\text { preparedness } \\
\text { planning }\end{array}$ & $\begin{array}{l}\text {-Transitional interventions vide provision of basic services ( food, healthcare, } \\
\text { education) and shelter } \\
\text {-Measures to sustain livelihood } \\
\text {-Participation of Finance, planning and infrastructure departments } \\
\text {-Participation of public service utilities (electricity, water supply etc.) } \\
\text {-Participation of Government local authorities in zones of high disaster risk } \\
\text {-Participation of Local NGOs and community based organisations } \\
\text {-Participation of Associations of professionals such as engineers and } \\
\text { architects }\end{array}$ & $\begin{array}{l}0.21 \\
0.19 \\
0.14 \\
0.12\end{array}$ & $\begin{array}{c}\text { Local administration } \\
\text { District, State and National } \\
\text { Disaster Management } \\
\text { Authority }\end{array}$ \\
\hline
\end{tabular}

\section{Discussions and Conclusions}

Despite the launching of several successful projects and programmes on disaster mitigation and enhancing disaster preparedness in India, the identification of metrics and standards for measuring disaster preparedness still remains a significant challenge. The domain of disaster preparedness being very complex, construction of an 
easily-comprehendible index to measure it was seemingly complicated. Moreover, the development of indicators which were measurable, practical and realistic was all the more difficult, given the diverse geo- climatic conditions and incidence of varied types of disasters in India. To facilitate the measurement of quantitative and qualitative aspects of disaster preparedness, direct and indirect indicators were developed by adopting subjective surveying undertaken by administering a questionnaire among different stake-holders concerning their perceptions on disaster preparedness. Seven core indicators identified through literature review which best represent the preparedness aspects in India were consistent with the results gathered through the questionnaire survey among experts. The measurement indicators developed here, were determined from a listing of indicators used in other models and was established through Analytical Hierarchy Process. To depict the relative importance of each contributing indicator to the index measurement, weightings were assigned to each indicator based on expert judgment process. The attributes pertinent to each core indicator, termed as sub-indicators; were also identified. A concise account of the indicators with key information about content, data requirements and proposed data sources was put forth. The spatial and temporal aspects associated were not within the scope of this paper. Nevertheless, they could be addressed by developing secondary data sets as add-ons to the core indicators; the identification of which demands further research. Future research should also focus on further refinement of indicator data for formulating Disaster Preparedness Indices. DPI is a pragmatic tool which helps to assess where a region stands with regard to its coping capability in case of an impending disaster. The trends in indicators reveal areas which need intervention. It facilitates a broader lens to look at the inherent weaknesses in the system as well as the good practices present else-where. Policy makers and other stake- holders may draw conclusions from these; which consequently would serve as strategic planning inputs.

\section{References}

[1] National Policy on Disaster Management, Ministry of Home Affairs, Government of India, 2009

[2] UNISDR (2015), Sendai Framework for Disaster Risk Reduction. Available at: http://www.unisdr.org/files/43291_sendaiframeworkfordrren.pdf

[3] Posadas, B., Seymour, A., Langlois, S., (2012). Community Disaster Preparedness Index-A Tool Designed to Measure Your Community's Disaster Preparedness. Centre for Urban Rural Interface Studies Mississippi State University. www.curis.msstate.edu

[4] Simpson, David M., (2006). Indicator Issues and Proposed Framework for a Disaster Preparedness Index (DPi). Draft Report of Disaster Preparedness Assessment Project by the Center for Hazards Research and Policy Development, University of Louisville, Draft version 1.0

[5] Davidson, Rachel, A., Shah, Haresh, C., (1997), An Urban Earthquake Disaster Risk Index, Stanford Digital Repository, John A. Blume Earthquake Engineering Center Technical Report 121. Available at: http://purl.stanford.edu/zy159jm6182

[6] Simpson, David M, (2008). Disaster preparedness measures: a test case development and application. Disaster Prevention and Management: An International Journal, Vol. 17 Iss: 5, pp.645 - 661 https://doi.org/10.1108/09653560810918658

[7] Freudenberg, M. (2003). Composite Indicators of Country Performance: A Critical Assessment. OECD Science, Technology and Industry Working Papers, 2003/16, OECD Publishing.https://doi.org/10.1787/405566708255

[8] Handbook on constructing composite indicators: methodology and user guide, Technical Report, OECD Publishing, Paris, 2008. Retrieved 25.03.2014 from: http://www.oecd.org/std/42495745.pdf

[9] JRC-EC State-of-the-art Report on Current Methodologies and Practices for Composite Indicator Development. Applied Statistics Group, Joint Research Centre, European Commission, Institute for Protection and Security of the Citizen Technological and Economic Risk Management, Ispra, Italy, 2002.

[10] Winderl, Thomas , Disaster resilience measurements - Stock taking of ongoing efforts in developing systems for measuring resilience, United Nations Development Programme, 2014. Available at: http://www.preventionweb.net/files/37916_disasterresiliencemeasurementsundpt.pdf

[11] Humanitarian Charter and Minimum Standards in Humanitarian Response ,The Sphere Project 2011 edition, Practical Action Publishing, Schumacher Centre for Technology and Development, UK, 2013. 